symptoms disappeared and laboratory tests became normal, although corticosteroid treatment was required for one year. There was no renal disease and the test for antibodies to denaturated DNA was positive.

We thank Dr E B Raftery for his help.

${ }^{1}$ Raftery, E B, and Denman, A M, British Medical fournal, 1973, 2, 452.

${ }^{2}$ Harrison, T, Sisca, T S, and Wood, W H, Postgraduate Medicine, 1976, $59,241$.

3 Peltier, A P, et al, Nouvelle Presse Médicale, 1974, 3, 649.

(Accepted 27 April 1979)

Departments of Cardiology and Immunohaematology, Hôpital Dupuytren, 2 Avenue Alexis Carrel, 87000 Limoges, France JULIEN BENSAID, MD, cardiologist

JEAN-CLAUDE ALDIGIER, MD, cardiologist

NORBERT GUALDE; MD, immunologist

\section{Croup associated with parainfluenza type 1 virus: two subpopulations}

Croup is a heterogeneous childhood condition of respiratory obstruc tion invariably affecting the larynx and occasionally the lower airways. It is often associated with virus infection, most commonly parainfluenza (PF) virus types 1 and $3 .^{1}$

\section{Patients, methods, and results}

When an adequate history was available one of us (DHK) subdivided patients with croup into two groups according to the prodromal illness. Those in group 1 had croup of sudden onset, either without prodromal coryza or, if present, of less than 24 hours' duration. Those in group 2 had had coryza for 24 hours or longer before the onset of croup. Because PF and mumps viruses are antigenically related we measured the antibodies in sera taken during the acute phase from 24 patients in hospital with croup to detect any differences between croup of sudden or gradual onset. PF1 had been isolated from the nasopharynx of all patients (14 in group 1 and 10 in group 2). Titres of neutralising antibody to PF1, 2, and 3 and mumps viruses were estimated in acute-phase sera $^{2}$ before the patient's group was disclosed to the laboratory. The mean age in group 1 was 2.4 years (table) compared with 2.3 in group 2 . Group 1 included eight boys and group 2 seven. Sera were taken a mean of 1.4 days after the onset of croup (not coryza) in both groups, but a mean of 1.4 days after the earliest signs in group 1 compared with 4.5 days in group 2 . A prodrome was present for a mean of $3 \cdot 1$ days before the onset of croup in group 2 .

Neutralising antibodies to one or more of the viruses were present in all the patients in group 1 compared with five in group $2(P<0.01)$. Moreover the geometric mean titre of total antibodies was 31 and 18.1 in groups and 2 respectively. Antibodies to PF3 were present in 11 of the patients in group 1 and four in group 2; there was no appreciable difference in the prevalence of antibodies to the other viruses. The geometric mean titre to PF1 (the infecting virus), however, was 40 in group 1 compared with 10 in group 2. The geometric mean titres to the other viruses were not appreciably different between the groups.

\section{Comment}

These serological differences support the division of cases of croup into subpopulations of sudden and gradual onset. The PF1

Comparison of patients with PF1 infection and croup of sudden or gradual onset

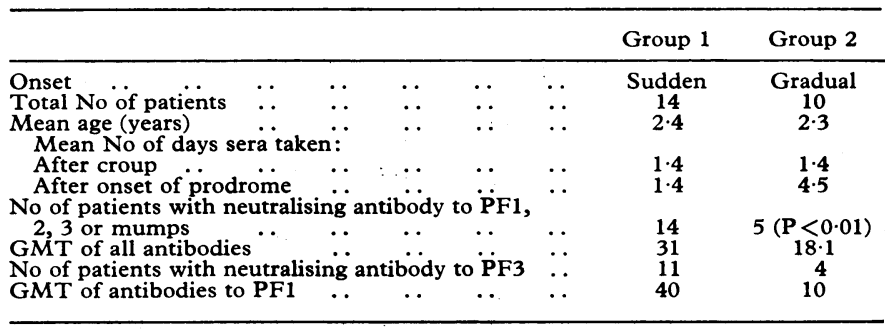

$\mathrm{PF}=$ Parainfluenza

GMT = Geometric mean titre. titres in group 1 were contrary to those expected if these antibodies resulted only from the current infection. An accelerated response resulted from previous infection with either PF1 or one of the other paramyxoviruses. PF3 is the most likely candidate because of its endemicity compared with the biennial appearance of $P F 1$ virus. ${ }^{13}$ In support of this, 56 out of $115(49 \%)$ PF3 infections in this hospital between 1964 and 1976 occurred in infants aged under 1 year compared with $20(13 \%)$ of 152 PF1 infections. ${ }^{3}$ We consider that there may be different pathogenic mechanisms between croup of sudden and gradual onset, the former resulting from prior PF3 infection and a subsequent hypersensitivity reaction to PF1 virus. A relevant observation is that $30 \%$ of children with PF3 infections have croup compared with $63 \%$ of those with PF1 infections.

Because of different opinions about the efficacy of steroid treatment in croup ${ }^{4}$ we believe that a double-blind trial based on the historical distinction between subpopulations may be of value, while further laboratory studies should investigate the pathogenesis.

${ }^{1}$ Buchan, K A, Martin, K W, and Kennedy, D H, fournal of Hygiene, $1974,73,143$

${ }^{2}$ Grist, N R, et al, Diagnostic Methods in Clinical Virology, 3rd edn. Oxford, Blackwell, 1979.

${ }^{3}$ Kennedy, D H, WHO Yearly Virus Report, 1977 (VIR 78.9), Annex 17 , p 55, Geneva, WHO, 1978

${ }^{4}$ Eden, A N, Kaufman, A, and Yu, R, fournal of the American Medical Association, 1967, 200, 403.

5 James, J A, American fournal of Diseases of Children, 1969, 117, 511.

(Accepted 20 April 1979)

Regional Virus Laboratory and University Department of Infectious Diseases, Ruchill Hospital, Glasgow G20 9NB

G E D URQUHART, MB, FRCPATH, consultant in clinical virology

D H KENNEDY, MB, MRCP, consultant in infectious diseases

J P ARIYAWANSA, MB, DIPBACT, registrar (now consultant virologist at Medical Research Institute, PO Box 527, Colombo 8, Sri Lanka)

\section{Diuretic escape and rebound oedema in renal allograft recipients}

Dependent oedema occurs often in renal allograft recipients, particularly during rejection episodes. Clinicians often prescribe potent diuretics to get rid of the excess salt and water. We have found that patients soon become dependent on the diuretics. We have therefore examined this problem in five patients who received cadaveric renal transplants.

\section{Patients, method, and results}

We analysed the records of four patients in whom daily collections of urine were made while frusemide was administered. All showed diuretic escape. We therefore studied an additional patient prospectively. Frusemide was prescribed at $40 \mathrm{mg}$ daily when the patient had clinical oedema. The dosage was increased to $80 \mathrm{mg}$ daily after about two weeks and continued for about four weeks before being abruptly withdrawn. Spironolactone was then introduced after five days and continued for about three weeks. Twentyfour-hour urine collections were made daily. Creatinine, sodium, and potassium concentrations were measured in aliquots by standard methods. Blood $(5 \mathrm{ml})$ was taken for estimations of plasma creatinine and sodium concentrations, the frequency of sampling varying from daily to weekly. Blood pressure, weight, and the presence or absence of oedema were recorded whenever blood was taken. Salt and water intakes were not restricted, and data were recorded for about 90 days. Throughout the study the patient's creatinine clearance was largely stable.

The figure shows the diuretic regimen, 24-hour urinary excretion of sodium, and plasma creatinine concentrations. Before treatment the 24-hour urinary sodium excretion was about $175 \mathrm{mmol}(\mathrm{mEq})$. This increased sharply to a peak of above $300 \mathrm{mmol}$ when frusemide was introduced, the increase lasting for about 10 days and returning to baseline levels at 14 days despite continued administration of frusemide. When the frusemide dosage was increased sodium excretion rose further to peak values above $400 \mathrm{mmol}$ in 24 hours, only to return to baseline levels again after two weeks. The second spurt in sodium excretion probably resulted from oscillations in balance between the diuretic and the patient's salt-retaining mechanism. When frusemide was stopped abruptly urinary sodium excretion fell to below $20 \mathrm{mmol}$ and the patient gained $2 \mathrm{~kg}$ overnight. Sodium excretion increased to baseline levels in six days and a further rise was induced by 